\title{
Index nominum ad Vol. 163
}

Ahlders, G., 148 Babenerd, J., 148 Barchet, S., 77 Baron, J., 14 Berzins, A., 101 Bettendorf, G., 134 Bloch, S., 209 Bossart, H, 348 (S) Breckwoldt, M., 134 Bfeãiák, M., 148 Brewer, Th. l·L, 425 (B) Cardis, R., 123 Chausse, J. M., 124 (S) Claude, J. M., 130 (S) Cordey, R., 124 (S) Crawford, J. S., 426 (B) Czeizel, E., 173 Czygan, P.-J., 134 Da Rugna, D., 247 (S) De Brux, J., 61 Dellepiane, G., 299 (S) Dupré-Froment, J., 61

Dvorak, O., 394 Fox, ËL, 371 Glatthaar, E., 316 (S) Göltner, E., 148, 235 Gömöri, Z., 247 (S) Groot, K., 134 Haering, M., 415 Hauser, G. A., 14 Herbinger, W., 1 Janda, J., 92 Janovski, N. A., 77 Jirásek, J. E., 14 Kañka, J., 115 Karsznia, R., 43 Keller, M., 187, 199 Keller, P. J., 159 Kittrich, M., 92 Klimek, R., 48 Kremer, H., 219 Krige, Z. F., 425 (B) Koller, Th., 379 Legerlotz, C, 407

430

Index nominum ad Vol. 163

Marsíková, L., 115 Mil, K., 115 Mintz, M., 61 Narik, G., 219 Neumayer, E., 228 Neuweiler, W., 27 Novak, M., 179 Onwudiwe, E. U., 27 Orban, G., 173 Österlund, K., 241 Quade, C, 235 Reisenauer, R., 115

R. Revaz, C, 127 (S) áabata, V., 179 Sen, D. K., 371 Spechter, H.-J., 303 (S) Stamm, O., 101 Stark, K. H., 228 Stäuble, K., 247 (S), 379 Teramo, K., 241 Uettwiller, A., 199 Weber, H., 101 Wichmann, H., 1 Widholm, O., 241 